\title{
The Crossed Adductor Reflex in Humans: An EMG Study
}

\author{
ROBERT D. TEASDALL, and H. VAN DEN ENDE
}

SUMMARY: Crossed adductor reflexes were recorded electromyographically in ten patients with bilateral lesions of the upper motor neuron. Three of these had a femoral neuropathy. Following blows directed to either the tendon of the adductor muscle or to the medial epicondyle of the femur, large amplitude responses of short latency were recorded from the ipsilateral adductor muscle while small amplitude responses of short latency and large amplitude responses of long latency were recorded from the contralateral adductor. The responses of short latency

RÉSUMÉ: Nous avons enregistré électromyographiquement les réflexes adducteurs croisés chez 10 patients avec lésions bilatérales des motoneurones supérieurs. Chez trois de ces patients il existait aussi une neuropathie fémorale. A la suite de percussions appliquées soit au tendon du muscle adducteur, soit à l'épicondyle médian du fémur, nous avons enregistré des réponses à grande amplitude et courte latence de l'adducteur ipsilatéral, et au contraire des réponses de petite amplitude et de longue latence furent observées à partir de l'adducteur contralatéral. Les réponses de which were recorded from the ipsilateral and contralateral adductor muscles ranged from 18 to $27 \mathrm{~ms}$. The contralateral responses of long latency ranged from 60 to $67 \mathrm{~ms}$. On tapping the patella or patellar tendon, large amplitude responses of short latency nere recorded from the contralateral adductor muscles while the ipsilateral adductor responses were absent. These responses resulted from stretch of the ipsilateral and contralateral adductor muscles. The contralateral responses were mediated across the midline by an extraspinal mechanical pathway.

courte latence enregistrées aur muscles adducteurs ipsi-et contralatéraux étaient de 18 à $27 \mathrm{~ms}$. Les réponses contralatérales de longue latence étaient de 60 à $67 \mathrm{~ms}$. La percussion de la région patellaire produisit des réponses de grande amplitude et courte latence aux muscles adducteurs contralatéraux alors que les réponses des muscles adducteurs ipsilatéraux étaient absentes. Ces réponses résultent de l'élongation des muscles adducteurs ipsi et contralatéraux. Les réponses contralatérales sont transmises à travers la ligne médiane par une voie mécanique extraspinale.
Part of this material was presented at meetings of the American Physiological Society, Atlantic City, N.J.. April 11, 1978 and the Canadian Congress of Neurological Sciences, Ottawa, Ont., June 20. 1980.

From the Division of Neurology, Department of Neurological Surgery and Neurology, Henry Ford Hospital, Detroit, MI 48202.

Reprint requests to Dr. Teasdall, Division of Neurology, Henry Ford Hospital. 2799 West Grand Blvd., Detroit, MI 48202, U.S.A.

\section{INTRODUCTION}

In patients with brisk tendon reflexes, contraction of muscles remote from the blow may occur in the ipsilateral and in the contralateral limbs. This phenomenon has been attributed to excitation of muscle spindle receptors at sites remote from the muscle stretched or tapped (Lance and DeGail, 1965; Teasdall and Magladery, 1974). In 1898 Sherrington demonstrated in the experimental animal that reflex activity induced by stretch may spread across the midline through pathways extrinsic to the spinal cord. This mechanism is different from the intraspinal conduction which is utilized for the crossing of other reflexes such as the crossed extension in the experimental animal (Sherrington, 1909) and the superficial abdominal in humans (Teasdall and Magladery, 1959). This EMG study was undertaken to determine the pathway of the crossed adductor reflex in humans.

\section{METHOD}

This study was performed in 10 adult patients with active crossed adductor reflexes. All were ambulatory with varying degrees of spastic weakness and extensor plantar responses due to spinal cord disease. Three had a femoral neuropathy in one of whom it was bilateral.

The patients were examined in the supine position with lower limbs abducted at the hips, flexed at the knees and the heels together. A pillow was placed under the knees for support. Adductor reflexes both ipsilateral and contralateral were elicited by means of a blow directed to either the tendon of the adductor magnus muscle just proximal to the medial epicondyle of the femur or to the medial epicondyle of the femur. In some patients, the blow was applied to 
the patella or the patellar tendon. An accelerometer, mounted at the base of the reflex hammer, triggered the sweeps of the oscilloscope when contact with the skin was made. The interval between contact and onset of the sweep was less than 0.4 millisecond (ms). Action potentials were recorded by means of electrodes fixed to the skin overlying the adductor muscles. On occasion, recordings were obtained from the quadriceps muscles. After amplification these potentials were displayed on the 2 beam oscilloscope of a TE-4 EMG machine. Each stimulus was repeated several times and the sweeps of the oscilloscope were photographed.

\section{RESULTS}

The responses from the adductor muscles following blows to either the tendon of the adductor muscle or to the medial epicondyle of the femur were divided into two groups on the basis of different latencies. Responses with latencies of 18 to $27 \mathrm{~ms}$ were recorded from ipsilateral and contralateral adductor muscles. The other responses, with longer latencies of 60 to $67 \mathrm{~ms}$, were recorded only from the contralateral adductor muscle. The results will be presented separately for these early and late responses.

\section{Early Responses}

These responses which were recorded from both adductor muscles in a patient with symmetrical crossed adductor reflexes are shown in Figure 1. In the upper paired tracings, the blow was applied to the tendon of the right adductor muscle and the recordings were made from the right adductor muscle in the upper tracing and from the left adductor muscle in the lower tracing. A response with a latency of $19.5 \mathrm{~ms}$ was recorded from the ipsilateral adductor muscle while the latency of the response from the contralateral adductor muscle was 27 ms. The amplitude of the ipsilateral response was greater than the contralateral. In the lower set of tracings, the blow was directed to the tendon of the left adductor muscle. Similar recordings were obtained from the ipsilateral and contralateral adductor muscles.

Following blows to the right and left medial epicondyles of the femurs in this same patient, ipsilateral responses of large amplitude with latencies of 19.8 and $18.5 \mathrm{~ms}$ respectively were recorded while corresponding contralateral responses were of smaller amplitude and had latencies of $\mathbf{2 0 . 2}$ and $22.0 \mathrm{~ms}$.

Similar observations on latency and amplitude of the adductor responses elicited by blows to the tendon of the adductor muscle and to the medial epicondyle of the femur were found in 6 other patients. The latency differences between these ipsilateral and contralateral early responses were less when the blows were directed to the medial epicondyle of the femur as compared to the tendon of the adductor muscle.

Early responses were also studied in 4 patients following a blow to the patella or patellar tendon. This stimulus evoked contractions of the ipsilateral quadriceps and contralateral adductor muscles, but no contractions of the ipsilateral adductor muscle were observed. The tracings of Figure 2 were recorded from the adductor muscles following a blow to the right patella and were representative of these findings. In the lower tracing, a response with a latency of 23 ms was recorded from the contralateral adductor muscle. The small displacement of the upper tracing, which was recorded from electrodes fixed to the skin over the ipsilateral adductor muscle, was due to spread of activity from the adjacent quadriceps muscle. On tapping the patellar tendon, the ipsilateral quadriceps response was larger in amplitude and the contralateral adductor response was smaller as compared to the responses which were obtained following blows to the patella.

In the 3 patients with femoral nerve involvement, early adductor responses were also recorded. The tracings of Figure 3 were representative and were obtained from a patient with wasting and weakness of both quadriceps muscles and absent knee jerks. The femoral nerves at the groins were inexcitable to electrical shocks. In the upper paired tracings, the blow was applied to the right medial epicondyle of the femur and action potentials were recorded from both adductor muscles. The ipsilateral response had a latency of $22 \mathrm{~ms}$ while the latency of the contralateral response was $26 \mathrm{~ms}$. In the lower pair of tracings, the blow was directed to the left patellar ligament. The response from the contralateral adductor muscle had a latency of $23 \mathrm{~ms}$ and was of the same configuration as the response which was obtained from this muscle on tapping the ipsilateral medial epicondyle (upper tracing of above pair). In the lower tracing, a response from the ipsilateral adductor muscle was not obtained. The deflection of the base line was an artifact and was due to movement of the electrodes caused by the blow. Similar recordings were obtained in this patient when the blows were applied to the right patellar ligament and the left medial epicondyle.

\section{Late Responses}

In order to record late responses, the sweeps of the oscilloscope were slowed. In Figure 4, the paired tracings were obtained from the ipsilateral adductor muscle. A large amplitude response from the ipsilateral adductor muscle and a small amplitude response from the contralateral adductor muscle with latencies of $23 \mathrm{~ms}$ were recorded. In addition, a large amplitude response from the contralateral adductor muscle with a latency of 60 $\mathrm{ms}$ was recorded. A late response from the contralateral adductor muscle with a latency of $67 \mathrm{~ms}$ was recorded from one other patient. Furthermore, these late contralateral responses were either abolished or decreased in amplitude when the contralateral limb was placed in an adducted position.

\section{DISCUSSION}

In most patients, the latency of the early response was several ms longer in the limb contralateral to the blow as compared to the ipsilateral response. These latency differences varied from 0 to $10 \mathrm{~ms}$ and the range was less when the blows were directed to the medial epicondyle of the femur as compared to those applied to the tendon of the adductor muscle. A satisfactory explanation for this observation has not been forthcoming. Furthermore, these latencies were of no assistance in determining the pathway of these crossed adductor responses. 
STIMULUS

tap-adductor muscle

$\mathrm{R}$
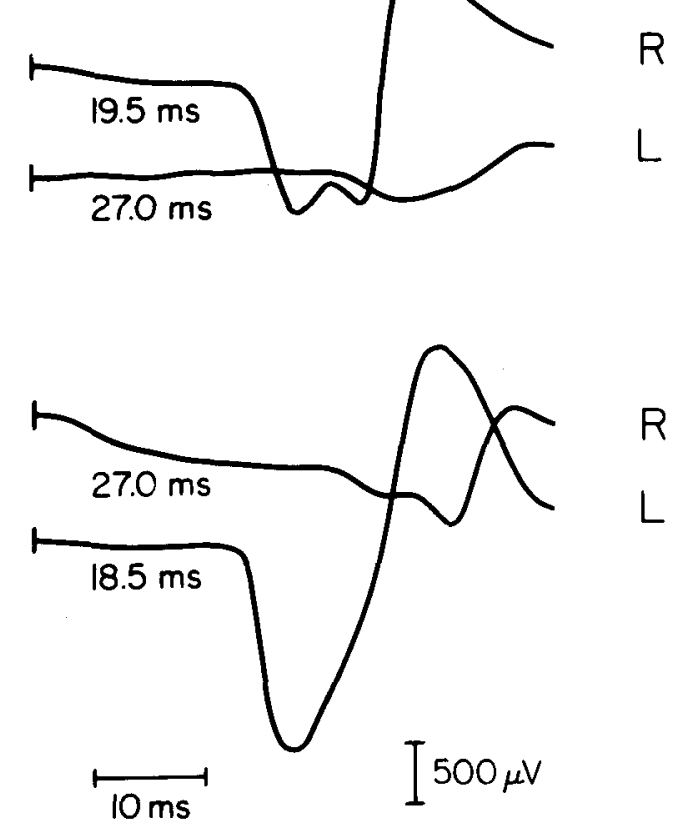

Figure I - In the'upper paired tracings, the blow was applied to the tendon of the right adductor muscle and in the lower paired tracings to the left. The upper tracing of each pair was recorded from the right adductor muscle; the lower from the left. Large amplitude responses were recorded from the ipsilateral adductor muscles while the contralateral responses were of smaller amplitude and longer latency.
STIMULUS

tap-patella

RESPONSE

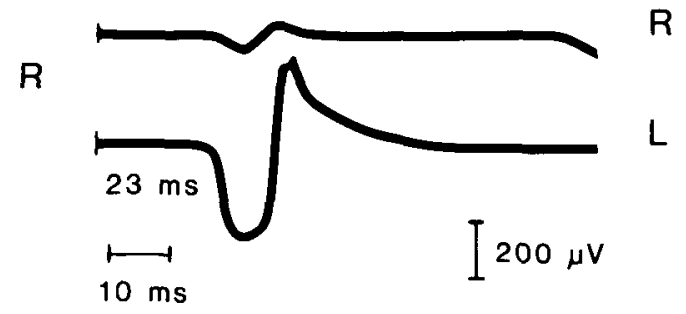

Figure 2 - The blow was applied to the right patella. The upper tracing was recorded from the right adductor muscle; the lower tracing from the left. A small amplitude ipsilateral response and a large amplitude contralateral response were recorded.
An intraspinal crossing for the contralateral adductor response was thought to be unlikely. This opinion was based on the assumption that several groups of muscles would be involved and the response prolonged if conduction across the midline occurred in the spinal cord. In our patients, these contralateral responses were recorded only from the adductor muscle and were of short duration.

The mechanism which was postulated for the early responses of the contralateral adductor muscle following blows directed to either the patella or patellar ligament is shown in Figure 5. On the left is illustrated the position of the limbs prior to the blow while the mechanical event which occurred immediately afterward is shown on the right. The blow to either the patella or patellar ligament, designated by the arrow, was directed along the axis of the femur which briefly tilted the pelvis. A shortening of the ipsilateral adductor muscle occurred together with lengthening of the contralateral adductor muscle. It was thought that stretch induced in this manner was responsible for the early response of the contralateral adductor muscle.

In order to test this hypothesis, acceleration along the axis of the femur was determined following a blow to the contralateral patella. This was measured in 2 patients by means of an acceleration transducer fixed to the skin overlying the patella. The tracings of Figure 6 from one of these patients were representative of the findings. In the upper tracing, the onset of the initial oscillation was recorded $2 \mathrm{~ms}$ after the blow to the contralateral patella. The second oscillation had attained maximal amplitude while the amplitude of the following oscillations gradually decreased to zero. These oscillations had a frequency of $200 \mathrm{~Hz}$ and lasted for $25 \mathrm{~ms}$. The oscillating displacement of the patella was calculated by intergrating acceleration with respect to time twice. The maximal displacement of the patella from the resting position was deter- mined to be $4 \mu \mathrm{m}$. In the lower tracing of this Figure, the response with a latency of $23.5 \mathrm{~ms}$ was recorded from the contralateral adductor muscle.

Matthews and Stein (1969) in the decerebrate cat were able to excite muscle spindles by applying stretch which oscillated at $100 \mathrm{~Hz}$ and had a peak to base line amplitude of $1.2 \mu \mathrm{m}$. In our patients, the early response of the contralateral adductor muscle was probably evoked by a short burst of the stretch oscillations which could well have accompanied the oscillations shown in Figure 6 and were produced by the blow to the opposite patella.

In both patients, the response of the transducer on the contralateral limb was about 10 times greater when the blows were applied to the patella or patellar tendon as compared to those directed to either the tendon of the adductor muscle or medial epicondyle of the femur. This finding was attributed to the fact that the latter blows were directed at a right angle to the long axis of the femur and the 
STIMULUS

RESPONSE

tap-medial epicondyle

$\mathrm{R}$

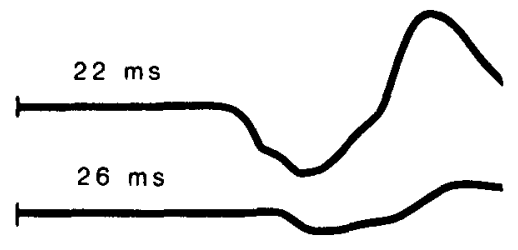

tap-patellar ligament

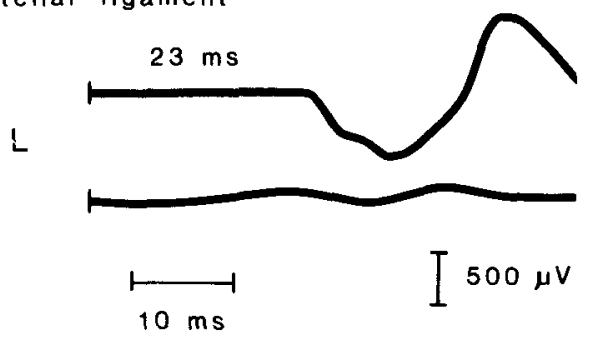

STIMULUS

RESPONSE

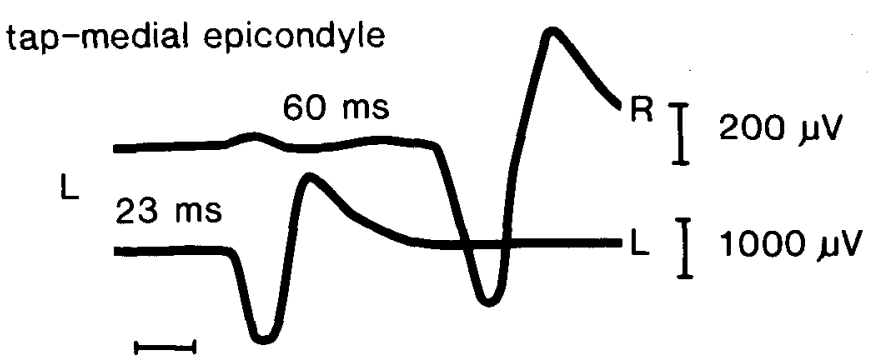

$10 \mathrm{~ms}$
Figure 3 - Patient with a bilateral femoral neuropathy. In the upper paired tracings, the blow was applied to the right medial epicondyle of the femur. The recording from the ipsilateral adductor muscle was of larger amplitude than that obtained from the contralateral adductor muscle. In the lower paired tracings, the blow was applied to the left patellar ligament. A large amplitude response was recorded from the contralateral adductor muscle while a small deflection was obtained from the ipsilateral adductor muscle.
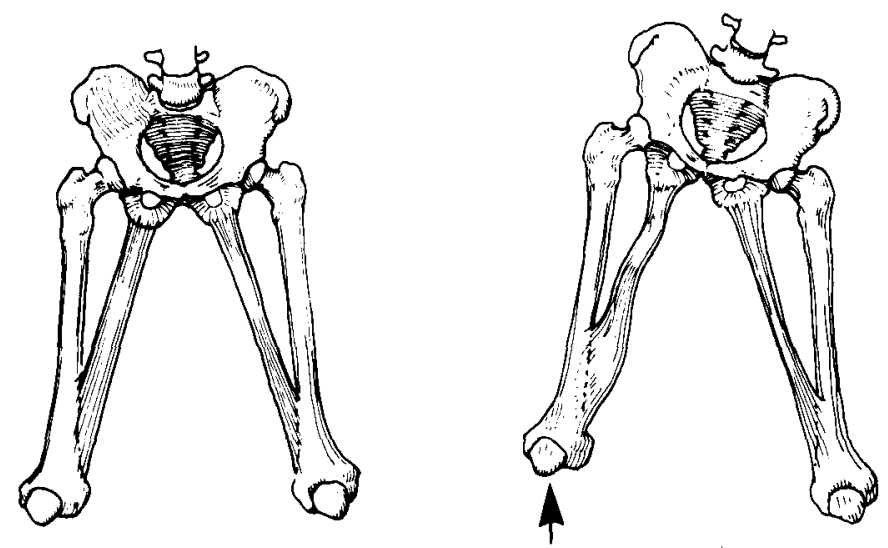

Figure 5 - Diagrams of the pelvis, femurs, adductor magnus muscles before and after the blow. The arrow designates the direction of the blow which was applied to either the patella or to the patellar ligament. The pelvis was tilted. The ipsilateral adductor muscle was shortened while the contralateral adductor muscle was stretched.
Figure 4 - The blow was applied to the left medial epicondyle of the femur. The upper tracing was recorded from the right adductor muscle; the lower tracing from the left. Two responses of different latencies were recorded from the contralateral adductor muscle. One response of short latency was recorded from the ipsilateral adductor muscle.

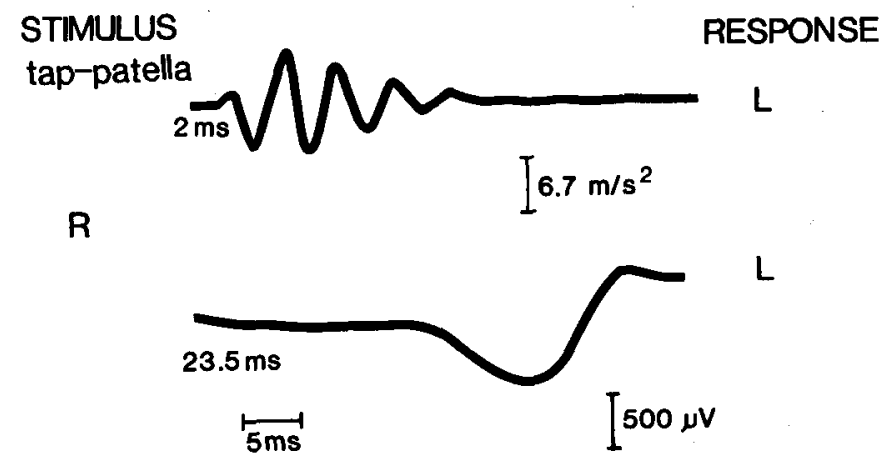

Figure 6 - The blow was applied to the right patella. In the upper tracing, acceleration along the axis of the femur was recorded by means of a transducer fixed to skin overlying the contralateral patella. In the lower tracing, the response was recorded from the contralateral adductor muscle. pelvis was not tilted to the same degree as with the patellar blows. This resulted in a corresponding decrease in stretch of the contralateral adductor muscle. Throughout this study it was repeatedly noted that the patellar blows were more effectual than blows to the patellar ligament in eliciting the early responses from the contralateral adductor muscles.

Contralateral adductor responses with longer latencies of 60 to $67 \mathrm{~ms}$ were also recorded. These late responses from the contralateral muscles were associated with large amplitude responses from the ipsilateral adduc- tor muscles. The ensuing contraction of the ipsilateral adductor muscle by tilting the pelvis, would stretch almost simultaneously the contralateral adductor muscle. The resulting stretch reflex might well explain these late responses from the contralateral adductor muscles. Support for this 
explanation was obtained from the following data. Latencies of 18 to 27 ms were associated with the early response from the ipsilateral adductor, 15 to $25 \mathrm{~ms}$ was utilized for the evolving contracting of the ipsilateral adductor (Cooper and Eccles, 1930) and another 18 to $27 \mathrm{~ms}$ was allowed for the late response from the contralateral adductor. Latencies of 51 to 77 ms were obtained which approximated the 60 to $67 \mathrm{~ms}$ range for these late responses from the contralateral adductor muscles. Furthermore, the observations that late responses from the contralateral adductor muscles were diminished or abolished by placing the contralateral limb in an adducted position would also be confirmatory.

\section{ACKNOWLEDGEMENT}

The authors thank Mrs. Marsha Ambrose for her assistance in the preparation of this manuscript.

\section{REFERENCES}

COOPER, S. and ECCLES, J.C. (1930). The isometric responses of mammalian muscles. J. Physiol., 69, 377-385.

LANCE, J.W. and DeGAIL, P. (1965). Spread of phasic muscle reflexes in normal and spastic subjects. J. Neurol. Neurosurg. Psychiatry, 28, 328-334.

MATTHEWS, P.B.C. and STEIN, R.B. (1969).
The sensitivity of muscle spindle afferents to small sinusoidal changes of length. J. Physiol., 200, 723-743.

SHERRINGTON, C.S. (1898). Experiments in examination of the peripheral distribution of the fibres of the posterior roots of some spinal nerves. II. (Croonian Lecture). Philos. Trans., 190B, 45-186.

SHER RINGTON, C.S. (1909). On plastic tonus and proprioceptive reflexes. Q.J. Exp. Physiol., 2, 109-156.

TEASDALL, R.D. and MAGLADERY, J.W. (1959). Superficial abdominal reflexes in man: A clinical and electromyographic study. Arch. Neurol. Psychiatry, 81, 28-36.

TEASDALL, R.D. and MAGLADERY, J.W. (1974). Brachioradialis reflex and contraction of forearm flexors. Arch Neurol., 30,9495. 